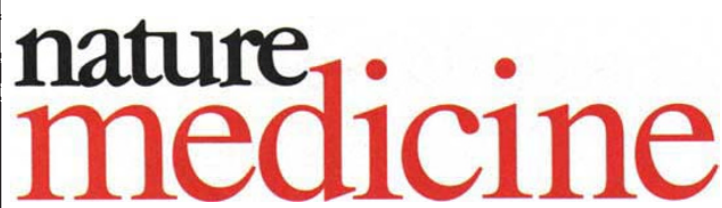

VOLUME 3 - NUMBER 11 - NOVEMBER 1997

\title{
Learning from scientific misconduct
}

A new scandal has reopened the debate on how to handle scientific misconduct, only this time the stage has been set in Europe. The number of papers co-authored by two prominent German biomedical researchers - Marion Brach of the University of Lübeck and her former colleague Friedhelm Herrmann of the University of Ulm - that appear to include fraudulent data has now risen to 47 , making this one of the most extreme cases of its kind and the first of this magnitude to strike Germany.

The Brach/Herrmann incident caught Germany completely off guard, and procedures for carrying out the inquest had to be established as the events unfolded. Despite this, German research establishments should be commended for the way in which investigations were handled. As soon as suspicions were brought to light, the four institutes where the alleged fraudulent research was conducted - the universities of Ulm, Lübeck, Freiburg and Berlin - were quick to establish investigative committees and to openly discuss their findings. The ministries of education - responsible for the hiring or firing of university faculty members were consulted and kept informed, as were the main funding agencies behind the work. Within six months, investigations led to the firing of Brach, who admitted to having manipulated data in some of the papers while under pressure from Herrmann. (The court case against Herrmann is ongoing, as he maintains that he had no knowledge of any wrongdoing.) There may be lessons to be learned from this latest episode.

In the past, the European scientific community played down the incidence of scientific misconduct. Currently, Denmark is the only country to have a national code of procedures to deal with such incidents. This apparent complacency stems from the fact that fraud has been viewed as being mostly a problem affecting the US, attributed in part to the highly competitive funding situation and the "publish-or-perish" attitude perceived to drive biomedical research.

In Germany, however, faculty is more securely funded - a concern often voiced by younger scientists is that those with more established positions feel little pressure to produce results - and the hierarchical nature of the German system makes it difficult for whistleblowers to speak out. Apparently, although postdoctoral researchers and more junior staff working closely with Herrmann and Brach had misgivings about aspects of their work, they were reluctant to make a public complaint for fear that their careers might be seriously threatened.

Another issue raised by this case concerns the level of responsibility co-authors should take for information presented in papers. Herrmann is claiming no knowledge of manipulation, stating that he was simply the supervising scientist. This response seems hardly appropriate, especially in light of the large number of publications that appear to be involved. Another scientist, Roland Mertelsmann, head of the clinical department of the University of Freiburg, co-authored 25 of the suspect publications. Although there is no indication that Mertelsmann was aware of any data manipulation, should he not also shoulder a share of the responsibility?

The task now facing German scientists is to consider these issues and to adopt a formal strategy for dealing with future scientific misconduct cases. Although a national oversight body exists in the US, the effectiveness of this Office of Research Integrity (ORI) has been called into question following the overturning and withdrawal of several prominent findings of scientific misconduct. Cases that have been brought to trial by ORI have been based on lengthy and very expensive investigations. Their subsequent reversal has done little good to promote public confidence in science, and these failed cases have also taken their toll on the personal and professional lives of those involved. Despite this attention, neither the ORI nor any other official group has spelled out the precise responsibilities of supervisors and department heads when junior colleagues go astray.

It is unlikely that Germany will establish a scientific oversight system based on the US example. Leading scientists in Germany are leaning more toward adopting a much less proactive and less centralized system, an important component of which will be the inclusion of mechanisms for protecting both whistleblowers and the accused scientists.

As a first step in this direction, the Deutsche Forschungsgemeinschaft (DFG) - the main granting agency in Germany - has set up an international commission of prominent scientists to discuss research standards (including those of co-authorship) and guidelines for scientific oversight that can be adopted in Germany and internationally. The first meeting of the DFG panel was held in September this year.

A sobering thought for all those concerned with science is that very little is known about the incidence of fraud or even what formally constitutes fraud. Regardless of how often it occurs, the German case has highlighted the need for a system that can deal with accusations fairly and rapidly. The extreme nature of the Brach/Herrmann episode has forced the German scientific community into taking a hard look at its research structure and to work toward establishing guidelines on scientific fraud. Other countries should follow this lead now, rather than waiting for a similarly damaging case to shock them into action. 